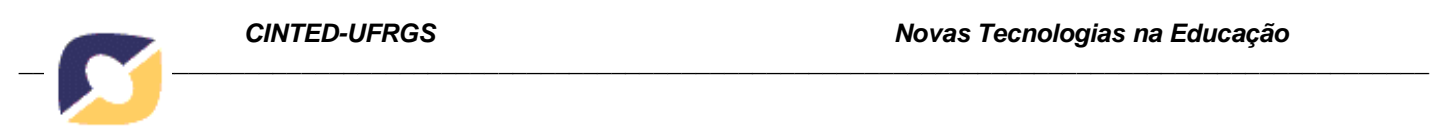

\title{
O computador como uma ferramenta para auxiliar na aprendizagem: a visão de alunos e professores
}

\author{
Ana Carolina Ribeiro Ribeiro \\ Patricia Alejandra Behar \\ Faculdade de Educação (FACED) / Núcleo de Tecnologia Digital Aplicada a Educação \\ (NUTED) / Universidade Federal do Rio Grande do Sul (UFRGS) \\ Porto Alegre - RS - Brasil \\ carolribeiro2@gmail.com,pbehar@terra.com.br
}

\begin{abstract}
RESUMO. O presente artigo trata da influência das tecnologias digitais na vida das crianças e como elas se fazem presentes no cotidiano escolar. O objetivo é analisar a concepção de professores e alunos sobre o uso das tecnologias, mais especificamente, o computador, em sala de aula e como ele pode auxiliar no processo de aprendizagem. Para tanto, foram levantados aspectos referentes à influência das tecnologias na vida das crianças e as mudanças no comportamento e nas habilidades resultantes dessa presença constante.
\end{abstract}

PALAVRAS-CHAVE: Ciberinfância. Computador na educação. Formação continuada

ABSTRACT. This article deals with the influence of the digital technologies in children's life and how they are present the school routine. The aim is to analyze how teachers and students think that tecnologies - the computer, remarkably - can help in the learning process in the classroom. For this, there were researched elements about the tecnologies' influence in children's life and the changing in their behaviour and abilities caused by this constant presence.

KEYWORDS: Cyber-childhood; Computer in Education; Training continued.

\section{INTRODUÇ̃̃̃O}

O presente artigo busca discutir e analisar a concepção de alunos e professores quanto ao uso de computadores como ferramenta de auxílio ao processo de aprendizagem. Nesse contexto, o foco desta pesquisa está na influência das tecnologias digitais na vida das crianças e como elas se fazem presentes no cotidiano escolar. Para tanto, foram realizadas entrevistas com crianças de três escolas públicas de Porto Alegre.

Vive-se em uma época de constantes mudanças, além da utilização cada vez mais acentuada das tecnologias digitais no cotidiano, uma série de características são recorrentes dessa convivência. Tentando acompanhar essas mudanças, diversos programas de governo buscam financiar e distribuir computadores para alunos e professores das escolas públicas. No entanto, muitas vezes não são realizadas capacitações para o uso dessas ferramentas e, sem saber como utilizá-las, os professores acabam por deixar de lado o uso das tecnologias em sala de aula. É fundamental, assim que, além da distribuição de computadores seja 


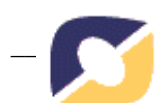

acompanhada de uma formação continuada dos professores, para que esses recursos não se percam em meio a uma estrutura já desgastada pelo tempo e desatualizada dos novos perfis de infância.

\section{TECNOLOGIAS DIGITAIS NO COTIDIANO}

$\mathrm{O}$ rápido desenvolvimento dos computadores nos últimos anos do século $\mathrm{XX}$ proporcionou máquinas com capacidade de processamento e armazenamento a preços sensivelmente mais acessíveis. Como resultado, observou-se desde então uma disseminação crescente dos computadores nos lares. Este fenômeno - que ainda é uma realidade proporcionou que grande parte das crianças hoje em idade escolar estabelecessem algum tipo de contato com essas máquinas.

Dentre os maiores atingidos por essa "onda" tecnológica encontram-se aqueles que deram seus primeiros passos já cercados por esse "novo mundo": as crianças de nossos dias já nasceram respirando esses ares revolucionários. Acostumados a operar vários aparelhos eletrônicos, utilizando-os, inclusive, para comunicar-se com seus amigos, esses "nativos digitais" (GUIMARÃES, 2012) apresentam uma intimidade com esses recursos que causa assombro aos adultos. Dessa forma, não seria exagero dizer que a tecnologia é uma das formas mais fluentes de expressão dos ciberinfantes (DORNELLES, 2005).

A preparação para trabalhar sob a luz desse novo paradigma, no entanto, não é suficiente, por si só, para garantir que o professor capte a frequência dos ciberinfantes. Se a infância hoje transita tão intensamente por meios virtuais, nada mais natural do que levar um pouco da sala de aula para essa dimensão.

Com as possibilidades inspiradas pela escalada aparentemente interminável da tecnologia, o governo brasileiro tem investido recursos em projetos que tem por meta ampliar o acesso da população aos computadores e à Internet, proporcionando, assim, a inclusão digital. De fato, é de se esperar que tais iniciativas sejam bem acolhidas, pelo menos inicialmente, por parte dos alunos - dos quais parcela não desprezível tem ou já teve algum contato com um computador e com a Internet. Porém, entusiasmar o aluno com a adoção de um recurso que lhe é atraente não é bastante para tornar a máquina em um elemento significativo para a sua aprendizagem. Trata-se, se não for levada em consideração uma prática pedagógica clara, de aproveitar em sala de aula uma "bagagem" que número não desprezível dos alunos já possui, com mais ou menos intensidade. Em resumo, o computador por si só é um suporte pródigo em potencialidades, pois depende de um plano cuidadoso que trace estratégias e explore sua latência enquanto ferramenta pedagógica. Naturalmente, isso pressupõe professores capacitados e fluentes no uso dessas tecnologias em sala de aula.

A percepção que se tem é que essa imagem - a do professor "plugado" e entusiasmado com a tecnologia - passa muito longe da realidade docente da escola pública brasileira. Um dos fatores apontados por Stahl (2003, p. 309) é "a falta de relação entre a formação recebida e as condições que o professor encontra na realidade escolar, exigindo conhecimentos e habilidades para as quais ele não foi preparado". De fato, no que tange à tecnologia, boa parte dos professores apresenta grandes dificuldades para adotá-la em seu cotidiano, enquanto, em outro extremo, seus alunos manipulam facilmente os aparelhos eletrônicos, dispensando, muitas vezes, qualquer instrução. Se o docente não possui um nível "mínimo" de domínio dos recursos apresentados pelas tecnologias digitais, falar em 


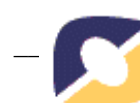

elaboração de estratégias pedagógicas que explorem as potencialidades por eles oferecidas esvazia-se de sentido.

\section{QUEM SÃO ESSES ALUNOS? ENTENDENDO OS CIBERINFANTES}

Atualmente, percebe-se uma mudança nas infâncias, nos espaços e nas relações infantis. As crianças estão imersas em uma nova cultura, da sociedade em rede, mostrandose atuantes na sua constituição e na construção de sua realidade. De acordo com Dornelles (2005), vive-se em meio a uma crise da infância, resultando em novos modos de se ver e se tratar as práticas com crianças. A criança passa a ser compreendida como alguém que pode estabelecer e produzir uma rede de práticas sociais, interagindo com outros atores sociais e com a produção de sua cultura (SCHNEIDER, 2007). A nova cultura, na qual as crianças estão inseridas, os espaços que as crianças ocupam atualmente, produzem infâncias globalizadas em contato direto com o mundo, atuando em uma cultura cibernética global com base em recursos multimídia.

Essa infância é definida por Dornelles (2005) como Ciberinfância. Uma infância globalizada, que é produzida nos espaços informatizados, multimídia e das novas tecnologias. São as crianças que constituem uma infância on-line, "daqueles que estão conectados à esfera digital dos computadores, da Internet, dos games, do mouse, do selfservice, do controle-remoto, dos joysticks, do zapping" (DORNELLES, 2005, p.80). Dessa maneira, dispondo de diversas ferramentas interativas, como os softwares sociais, e fazendo-se presentes na cibercultura ${ }^{1}$, essas crianças estão encontrando novas maneiras de se sociabilizar e de se produzir como sujeitos infantis. Vê-se, assim, a criança como parte da sociedade, com um modo próprio de pensar, relacionando-se e interagindo com membros de seu contexto social, tornando-se atuantes eu seu meio.

O Homo Zappiens, definição Veen \& Vrakking (2009) par a Ciberinfância, constitui-se como uma nova geração que está atuando em uma cultura cibernética global, baseada na multimídia. Para os autores, essa nova geração produz uma nova espécie, uma vez que apresenta um comportamento diferenciado de outros tempos, sendo mais ativa, direta, impaciente, incontrolável e indisciplinada. Essa geração se difere, também, de todas as outras, pois cresce em uma era digital e muitos foram os meios que proveram essas mudanças. Os autores destacam, pelo menos, três aparelhos que influenciaram de maneira significativa na constituição dessas mudanças: o controle-remoto da televisão, o mouse do computador e o telefone celular. $\mathrm{O}$ controle-remoto fez com que as crianças pudessem escolher e assistir a uma infinidade de canais nacionais e estrangeiros; Com o mouse, os alunos navegaram na internet e clicam até que achem o que quiserem, buscando ícones, sons e movimentos mais do que propriamente letras; Com o celular, puderam se comunicar com os pais e com os amigos com maior facilidade, pois a distância física não representa restrição à comunicação.

\section{DESENVOLVIMENTO DA PESQUISA}

Para o desenvolvimento dessa pesquisa, escolheu-se a realização de entrevistas com crianças e professores das Séries Iniciais do Ensino Fundamental, com o intuito de

\footnotetext{
${ }^{1}$ Cultura própria contemporânea marcada pelas tecnologias digitais resultante da convivência no Ciberespaço (LEMOS, 2010).
}

V. $10 \mathrm{~N}^{\mathrm{o}} 1$, julho, 2012 
compreender como eles acreditam que o computador pode auxiliar nas aprendizagens e em sala de aula. Para isso três escolas públicas da rede estadual de Porto Alegre foram contatadas e, de acordo com a disponibilização de tempo e espaço, foram realizadas as entrevistas. Essas buscavam conhecer e compreender as demandas e expectativas quanto ao uso de recursos computacionais por alunos e professores na escola. Além disso, buscou-se conhecer o contexto em que os alunos que estão envolvidos, sobre seus gostos e a disponibilidade de computadores para que pudessem utilizar. Cabe destacar que essas escolas ainda não são participantes de programas do governo que visam distribuir computadores para seus alunos, mas possuem laboratórios equipados com computadores e internet.

As perguntas feitas para as crianças participantes buscaram analisar os modos de utilização do computador no seu cotidiano, além da visão que elas possuíam da possível utilização do computador no cotidiano escolar.

- Você usa computador? Onde?

- O que você acha de computadores?

- O que você faz no computador?

- Você já usou um computador na escola? Como?

- Como você acha que o computador pode ajudar na aprendizagem?

- Acha que seria possível utilizar um computador em sala de aula? Como?

As perguntas realizadas para os professores buscaram analisar a concepção que os mesmos possuíam do uso do computador, além da observação do uso feito pelos seus alunos.

- Você acha que o computador pode ajudar na educação? Como?

- A escola disponibiliza computadores para uso dos alunos ou exclusivamente de professores?

- Já usou computadores ou equipamentos eletrônicos em aula? Como?

- Acha que a utilização de computadores pode fazer diferença na aprendizagem das crianças?

- As crianças demonstram interesse em utilizar computadores na escola?

- Observa o uso de computadores por crianças em trabalhos que são solicitados? (Por exemplo: trabalhos digitados, trechos de textos copiados de sites).

- Já fez algum curso de formação continuada para a utilização de computadores em aula? Se sim, qual o foco do curso?

A pesquisa contou com 53 alunos do $1^{\circ}$ ao $4^{\circ}$ ano do Ensino Fundamental que possuíam entre seis e 13 anos. Inicialmente, seriam realizadas 87 entrevistas, mas de acordo com a aceitação dos pais e retorno dos termos de consentimento, 34 entrevistas não puderam ser realizadas. A quantidade de entrevistas se daria de acordo com o número de alunos de cada turma, na busca de um conhecimento sobre a diversidade de alunos que são encontrados em escolas públicas.

Sobre a população pesquisada, cabe destacar que desses alunos, $77 \%$ possuem computadores em casa, sendo que os outros $23 \%$ utilizam-no em lan houses ou na casa de 


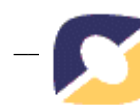

parentes. Essas crianças, também utilizam freqüentemente programas como MSN, Orkut e realizam diversas pesquisas.

Os dados coletados permitiram a elaboração de categorias de análises, de acordo com a proposta de Moraes (1999), para a análise de conteúdos. Assim, de acordo com essa metodologia, é proposto um conjunto de fundamentos e procedimentos específicos para a análise de dados qualitativos. A partir desse estudo e das análises das respostas obtidas nas entrevistas, foram elaboradas quatro categorias de análise que serão descritas a seguir.

A discussão apresentada é o resultado das interpretações das pesquisadoras, apoiadas no uso dos extratos retirados da fala dos sujeitos entrevistados. Os nomes não serão utilizados para preservar a identidade dos participantes. Os trechos apresentados a seguir apresentam as respostas mais recorrentes entre os alunos participantes da pesquisa.

\section{- O computador como um bem de inúmeras possibilidades}

Essa categoria apresenta as perspectivas dos alunos sobre o computador como parte do dia-a-dia, a partir do uso que é feito e das análises de suas possibilidades. A ênfase se dá nas respostas dos alunos, pois são o foco dessa pesquisa e é fundamental para a compreensão da visão dos alunos, tomar conhecimento do uso é feito em seu cotidiano.

Acho que os computadores têm coisas boas e coisas boas e coisas ruins, mas, infelizmente, as pessoas só usam os computadores para coisas ruins.

Menina (12 anos) $-4^{\circ}$ ano

Legal, divertido e também pode me ensinar muitas coisas.

Menino (sete anos) $-1^{\circ}$ ano

Muito interessante, porque podemos nos informar sobre tudo o que acontece no mundo. Menina (nove anos) $-3^{\circ}$ ano

Computador é um meio de comunicação muito bom e rápido, mas deve ser usado com cuidado e limite.

Menino (oito anos) $-3^{\circ}$ ano

A partir desses extratos, pode-se perceber que o computador é visto de diferentes maneiras pelas crianças e, na maioria das vezes como algo benéfico para a vida delas. Pode-se perceber, através da fala da menina de 12 anos, certo receio no uso do computador, visto que, de acordo com ela, sãs pessoas utilizam para coisas ruins. Quando questionada sobre o que seriam essas coisas ruins, a menina fez menção a falas de sua mãe, que é cuidadosa no uso do computador, deixando que ela utilize-o apenas na sua presença. No entanto, ela não soube explicar o que de fato é ruim no computador. Com certa semelhança nas respostas, o menino de oito anos comenta que o uso do computador, mesmo que seja bom e rápido, deve ser feito com cuidado e limite. Atualmente, uma pesquisa realizada pelo canal de TV Nickelodeon mostrou que 68\% dos pais de crianças entre quatro e 14 anos, realizam algum tipo de controle sobre o que os seus filhos acessam pela internet. Desses $68 \%, 43 \%$ realizam pesquisas freqüentes para checagem de contatos e amigos no MSN e no Orkut e $31 \%$ visita os históricos de acessos após o uso feito pelas crianças. Além disso, na internet, já são disponíveis diversos "programas de controle parental" que buscam bloquear os sites que não são recomendados para crianças ou que os pais não querem que elas criança visitem. Além disso, é possível realizar um monitoramento do que é visitado por 


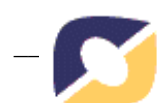

elas. Percebe-se assim, um grande interesse dos pais sobre o que os seus filhos e, com razão, devido aos inúmeros casos de pedofilia e pesquisas sobre informações pessoais que possam ser utilizadas por pessoas desconhecidas.

Nos extratos das outras crianças, pode-se perceber que o computador é visto como um recurso ilimitado e cheio de possibilidades, onde se pode aprender "todas as coisas do mundo" e que pode ensinar os mais diversos assuntos.

\section{- Meio de entretenimento}

A categoria meio de entretenimento agrupa as possibilidades citadas pelas crianças, sobre o computador como um meio de grandes possibilidades de diversão, para conversas e acesso a informações. Compreendendo o uso que as crianças fazem do computador, podese entender o porquê de suas opiniões sobre o uso em sala de aula, por exemplo.

Eu jogo online, olho vídeos e quando vem tema de pesquisa eu faço no computador.

Menino (oito anos) $-3^{\circ}$ ano

Jogo jogos de menina, pimbal e olho alguns vídeos. Também escuto música e brinco no Paint.

Menina (sete anos) $-1^{\circ}$ ano

Eu jogo e falo com meus primos.

Menino (sete anos) $-2^{\circ}$ ano

Eu olho minhas mensagens, mecho e converso com meus amigos no MSN e jogo no computador. Também ouço músicas.

Menino (13 anos $)-4^{\circ}$ ano

Com esses extratos é possível perceber a disseminação do uso do computador nos lares brasileiros, nos mais diversos contextos e para usos de diversas maneiras. Entre os as funções mais comentadas, estão o uso do Orkut, a realização de conversa pelo MSN Messenger, participação em jogos, além de assistir vídeos.

Um dos extratos que chamam a atenção é quando a menina de sete anos comenta jogar jogos de menina. Percebe-se o quanto o discurso de que existem objetos determinado para meninos e meninas se faz presente desde muito cedo. Além disso, ao fazer uso de sites e jogos infantis, a criança é exposta signos, já que não se consome apenas o objeto em si, mas tudo o que ele pode representar para meninos e meninas, como status, conforto, desejo e beleza, saber e poder. Esses fatos podem ser facilmente verificados em um site muito utilizados por meninas, como um típico "site de menina", ou seja, o site da Barbie. Já de início pode-se perceber que as cores giram apenas entre tons de rosa determinando uma cor específica para meninas. Além disso, como afirma Dornelles (2005, p. 35), "as crianças tem brincado apenas com um tipo de boneca, ou seja, uma boneca como a Barbie, magra, branca, bela e como as princesas dos filmes". Dessa maneira, é evidente a influencia que sites como esses podem fazer na construção da identidade de crianças e nos modos de ser criança na contemporaneidade.

\section{- Ferramenta para o processo de aprendizagem}




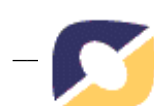

Essa categoria visa analisar a visão dos alunos sobre como eles imaginam que o computador pode auxiliá-los em suas aprendizagens. Além disso, busca analisar como os professores veem essa ferramenta presente nos trabalhos de seus alunos e se eles acreditam que ela possa fazer diferença no processo de aprendizagem das crianças.

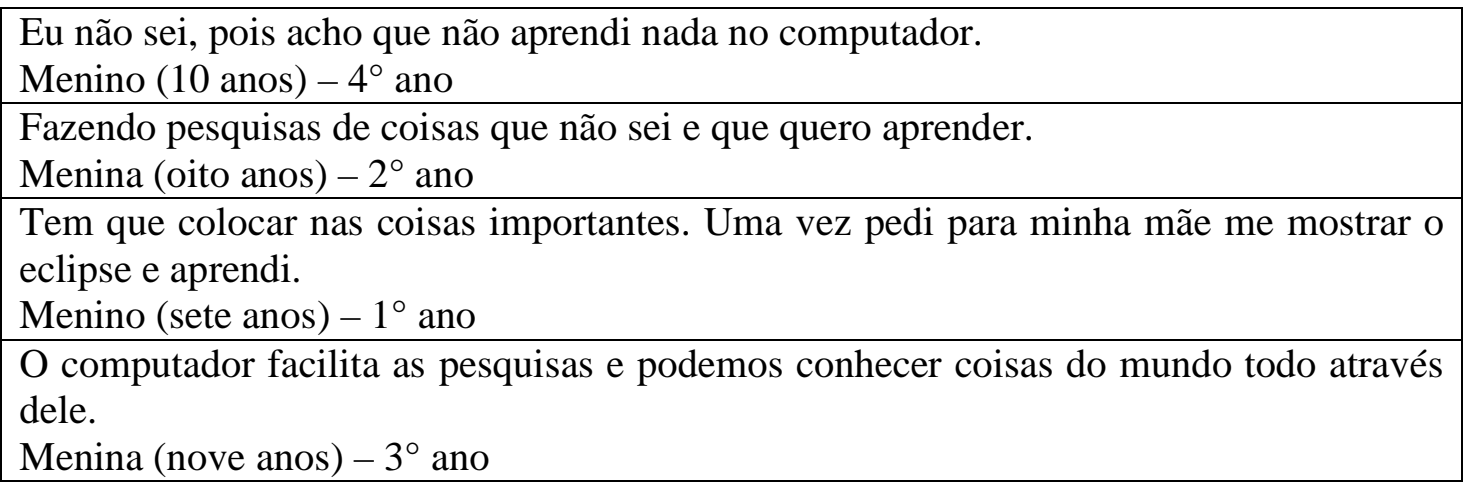

Esses extratos mostram como o computador é visto como um recurso de grande auxílio para as crianças, mesmo que não saibam a potencialidade de uso dessas ferramentas. Todos os comentários sobre o uso do computador como benéfico para a aprendizagem mostram-no como uma espécie de enciclopédia virtual, como um repositório de informações que são utilizadas para a resolução de problemas e para a realização de pesquisas. Além disso, através de seus relatos, podem-se perceber as possibilidades e crenças que ele passa, já que as crianças acreditam ter acesso ilimitado às mais diferentes informações. Percebe-se que, de fato, mesmo que suas práticas não sejam construtivas, como o relato de menino do $4^{\circ}$ ano, eles acreditam que podem aprender muito na utilização do computador, além de relatar que o utilizam para o desenvolvimento de trabalhos escolares e pesquisas diversas. Como comentado no referencial teórico, as tecnologias aumentam as possibilidades de aprendizagem quando abrem o espaço para perguntas, armazenamento e manipulação de informações e divulgação de descobertas. Assim, as práticas pedagógicas devem contemplar as construções coletivas dos conhecimentos dos alunos através das tecnologias, onde os professores intermedeiam e orientam os alunos durante esse caminho. A utilização das tecnologias digitais na educação proporciona uma maior interatividade e a não linearidade nos processos das aprendizagens. Além disso, as crianças precisam desenvolver uma capacidade crítica que lhes permita compreender como a informação produzida, disseminada e consumida e como ela adquire significado.

Traz acesso a quem não tem, motiva os alunos a aprenderem coisas novas, desenvolve a coordenação motora fina e a atenção.

Professora do $3^{\circ}$ ano

Desde que haja um aproveitamento dirigido e com recursos próprios a cada conteúdo a ser trabalhado.

Professora do $4^{\circ}$ ano

Não faço esse tipo de trabalho com crianças do $2^{\circ}$ ano.

Professora do $2^{\circ}$ ano

De acordo com o relato das professoras, em parte, apresenta certo interesse na utilização das tecnologias para a aprendizagem. Apesar da professora do $2^{\circ}$ ano especificar 


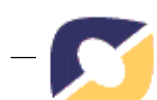

que não faz esse tipo de trabalho com crianças de sua série, por acreditar que eles não tenham capacidades, sabe-se que desde muito cedo as crianças já estão inseridas em meio digital. Além disso, nenhuma das professoras relatou que as tecnologias façam parte de sua prática promovendo o que foi relatado por elas.

\section{- Recurso didático-pedagógico em sala de aula}

Essa categoria analisa como os alunos entendem que o computador possa ser utilizado em sala de aula e se ele pode auxiliá-los no cotidiano escolar. Por parte do professor é analisado como ele pensa a sua prática pedagógica contando com o auxílio dessa ferramenta.

Não, porque pode atrapalhar a professora.

Menino (sete anos) $-1^{\circ}$ ano

Não, eu acho que não porque na aula nós estudamos, só se for na informática.

Menina (10 anos) $-4^{\circ}$ ano

Não, na aula a gente usa caderno.

Menino (13 anos) $-4^{\circ}$ ano

Sim! Às vezes os professores dão coisas para pesquisar em casa e tem gente que não tem condições de ter computador. Será bem educatível (sic) para as crianças que não tem computador em casa.

Menina (12 anos) $-4^{\circ}$ ano

Sim, uma vez por semana os alunos poderiam ter uma hora para trabalhar com o computador, dando oportunidade aos que não tem computador em casa.

Menina (nove anos) $-3^{\circ}$ ano

É surpreendente nessa categoria, a visão da maioria dos alunos, de que o computador não pode ser utilizado em sala de aula. Diferentemente de seus relatos sobre o uso do computador para auxílio à aprendizagem, as crianças não concebem seu uso em sala de aula, já que estão acostumados com uma cultura escolar fechada e pré-determinada. Mesmo que esses recursos façam parte do dia-a-dia dos alunos e dos trabalhos escolares, não seria adequado, segundo eles, utiliza-lo em sala de aula.

Sim, para revisão e fixação dos conteúdos desenvolvidos em aula.

Professora do $2^{\circ}$ ano

Não. Os alunos utilizam com a professora de informática.

Professora do $3^{\circ}$ ano

A escola precisa de professores capacitados e disponibilizados a encarar esse novo ícone que é a informática educativa sem medo de que algum dia seja substituído por computadores. É preciso então que haja uma integração entre o meio escolar e o corpo docente, desenvolvendo assim a sociabilidade dos alunos e a familiaridade dos professores com o mundo da tecnologia.

A aprendizagem acontece por meio da descoberta, da experimentação e da investigação. Nesse sentido, pode-se dizer que a tecnologia aumentou as possibilidades de 


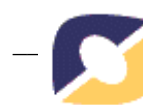

se aprender com os meios de comunicação, simulação, autoria e informação. O comportamento do aluno zappiens enquanto aprende está mudando com as diversas formas de interação social, já que eles interagem com as paginas de sites observando tanto textos escritos, como textos icônicos, imagens e cores, como possíveis entradas a seguir na construção de caminhos de leitura diante de uma grande variedade de informações. Assim, a experiência de aprendizagem se dá através da exploração das informações e ambientes e através da colaboração em rede com outros usuários. Com isso, as relações sociais, estabelecidas no meio virtual, são vistas como uma grande vantagem para a construção de soluções para problemas encontrados. O professor atento à estrutura de aprendizagem do aluno zappiens "aprender fazendo" deve desafiá-lo para o "aprender refletindo", com práticas pedagógicas que contemplem as construções coletivas usando as tecnologias para abrir o espaço de perguntas, de armazenamento e manipulação de informações e divulgação de descobertas, aumentando as possibilidades de aprendizagem. O desafio é aproximar o que os alunos fazem na escola do que fazem em suas horas de lazer, para que as situações de aprendizagem na escola também sejam motivadoras, desafiadoras e divertidas.

\section{CONSIDERAÇÕES FINAIS}

A partir dessa pesquisa foi possível constatar que muitos alunos, mesmo que utilizam diariamente o computador, acreditam que ele não auxilia em sua aprendizagem e ao utilizá-lo cotidianamente não estão aprendendo nada. Sabe-se que, de certa forma, essa visão é fruto de uma educação que segue padrões determinados de escolarização, não abrindo espaço para práticas diferenciadas e que estejam de acordo com as vivencia dos alunos. Percebe-se, assim, o quanto a cultura escolar, na determinação de práticas e modos de transposição didática, comportamentos e normas sociais realizadas na escola, dificultam a disseminação de diferentes métodos e recursos.

A partir do objetivo de pesquisa, que consiste em investigar o olhar de alunos e professores sobre o uso do computador como uma ferramenta que auxílio ao processo de aprendizagem, pode-se perceber que os discursos de alunos e professores não correspondem à prática. Os alunos veem o uso do computador de uma maneira muito rica $\mathrm{e}$ cheia de possibilidades para pesquisas e aprendizagens. No entanto, ao analisar o seu uso em sala de aula, não conseguem aliá-lo as práticas ao que estão acostumados, salientando que para aprender é necessário o uso de caderno e atenção. $\mathrm{O}$ mesmo pode ser relatado em relação aos professores. Ao analisar o uso do computador, relatam que esse recurso é de uso exclusivo da professora da sala de informática demonstrando não saber o que é tradado nesses momentos. Em tempos de diversos programas que financiam e distribuem computadores, pouco se pode esperar de um uso que explore todas as suas potencialidades e que seja de importância em sala de aula.

Espera-se, com esses resultados, proporcionar aos professores uma reflexão sobre suas práticas de modo que, antes mesmo de aderirem a diferentes recursos reflitam sobre a prática que estão desenvolvendo em sala de aula, buscando uma troca com seus alunos e reformulando sua prática através das idéias deles.

\section{REFERENCIAS}


DORNELLES, L. V. Infâncias que nos escapam: da criança da rua à criança cyber. Petrópolis, RJ: Vozes, 2005.

GUIMARÃES, L. S. R. O aluno e a sala de aula virtual. In: LITTO, F. \& FORMIGA, M. (orgs). Educação a distância: o estado da arte. Volume II. São Paulo: Pearson Education do Brasil, 2012.

LEMOS, A. Cibercultura: Tecnologia e vida social na cultura contemporânea. Ed. Sulina, Porto Alegre, 295 p., 5a Edição, 2010.

MORAES, R. Análise de Conteúdo. Revista Educação. Porto Alegre. № 37. Março, 1999

STAHL, M. M. Formação de professores para o uso das novas tecnologias de comunicação e informação. CANDAU, V. M. (org.). Magistério: construção cotidiana. Petrópolis, RJ: Vozes, 2003.

SCHNEIDER, D. Planeta ROODA: desenvolvendo arquiteturas pedagógicas para Educação Infantil e Anos Iniciais do Ensino Fundamental. Dissertação (mestrado) universidade Federal do Rio Grande do Sul. Faculdade de Educação. Programa de Pósgraduação em Educação, Porto Alegre, RS, 2007

VEEN, W; VRAKKING, B. Homo Zappiens: Educando na era digital. Porto Alegre, Artmed. 2009 